\title{
An Innovation Performance Evaluation and Decision Model For Computer-Aided- Innovation Projects
}

\author{
Ruihao Wang \\ School of Economic \& Management, Tongji University, Shanghai, China
}

\begin{abstract}
Proposed a quantitative model for enterprises to make decision in the investments of Computer Aided Innovation (CAI) projects, based on investigations in 12 cases. The model considered the principle of performance-based budgeting, consisting of three main components: (A) a performance indicator system consists of 5 domains, (B) a nonlinear evaluation algorithm based on innovation project risk theory, $(\mathrm{C})$ a theoretical model for budget decision on the project investment. Part of the model has been verified and applied in some corporations. The paper discussed the performance evaluation model and the budget decision model, and compared the evaluation results from the model to that from professional experts.
\end{abstract}

\section{Keywords - Computer Aided Innovation (CAI), Innovation Management, Investment Decision}

\section{RESEARCH BACKGROUND}

Computer-Aided-Innovation (CAI) means that applying information technology to improve industry innovations, including knowledge management, collaborative design and e-training systems. CAI is more and more popular and important in enterprises nowadays. For example, in the 43 construction design corporations investigated in Shanghai, 38 of them have invested or are planning to invest in developing online-collaborative-design platforms. However, the risk of these CAI projects is generally very high, since the benefits of both IT projects and innovation projects are unclear in nature. In fact, many of such projects did not return benefits as expected, and the investment plan was finally proven to be wrong. To resolve the problem and improve the effect of CAI project management, we held a long-term investigation on some typical projects and propose a solution model.

During the investigation, we have examined 12 various CAI projects, and table 1 shows some major features of the sample. The investigating methods include field-inquiry and questionnaire, snapshot review in production system, data integration test on production system, walk-through test in function line, and Delphi review method.

TABLE I. THE INVESTIGATION SAMPLE DisTRIBUTION

\begin{tabular}{|c|c|c|c|}
\hline $\begin{array}{c}\text { Application } \\
\text { Type }\end{array}$ & $\begin{array}{c}\text { Knowledge } \\
\text { Management }\end{array}$ & $\begin{array}{c}\text { Collaborative } \\
\text { Design }\end{array}$ & E-Training \\
\cline { 2 - 4 } & 4 & 5 & 3 \\
\hline $\begin{array}{c}\text { Budget Scale } \\
\text { (RMB 1,000) }\end{array}$ & Less than 100 & $100-1,000$ & $\begin{array}{c}\text { More than } \\
1,000\end{array}$ \\
\hline
\end{tabular}

\begin{tabular}{|c|c|c|c|}
\hline & 3 & 8 & 1 \\
\hline \multirow{3}{*}{ Project Type } & $\begin{array}{c}\text { Wholly New } \\
\text { Application }\end{array}$ & $\begin{array}{c}\text { Upgraded } \\
\text { Application }\end{array}$ & $\begin{array}{c}\text { Embedded in } \\
\text { ERP }\end{array}$ \\
\cline { 2 - 4 } & 7 & 3 & 2 \\
\hline
\end{tabular}

Through the investigation, we concluded that the lack of an effective performance evaluation model has obviously affected the effect of more than half CAI projects in three ways: (1) Redundancy construction, includes functionredundancy among different systems in a same enterprise, and data-redundancy among different systems. (2) Low customer satisfaction, includes complaints from users for inconvenient operations and useless information, and the complaints from system managers for the complex workflows which reduce work efficiency. (3) Low sustainability, includes low capacity to fit the change of innovation requirements and to be the base platform for future extending.

In this paper, we proposed a solution to solve the problem, which is, to build up a performance based investment decision model for CAI projects. The framework consists of two models: a performance evaluation model and a budget decision model. The core one is a quantitative scoring model and has been applied in evaluation works in some enterprises.

\section{BRIEF INTRODUCTION OF EXISTING RESEARCHES}

Performance evaluation and related decision method has been applied into management area for more than 50 years in developed countries such as USA and UK. From 1990s, information system projects have been a huge investment for these countries, and required an advanced special performance based budgeting framework to meet the complexity and specialization of information systems. In 2002, USA government proposed the "Performance Reference Model (PRM)" as a part of the "Federal Enterprise Architecture (FEA)", which can be used in project performance evaluation in collaboration with the form A300 and the other models in FEA [4]. This model provides a series of general indicators, which can be adapted to individual forms by each evaluated department, include education institutions. This model has been applied in federal budgeting decision since BY 2004, and obviously improved the manage efficiency. In China, such researches are few. Peng Xizheng discussed the basic concept of performance evaluation in [5]. Mi Hong proposed a pre-assessment index system in [6].

In our investigation in some enterprises interest in CAI systems, we analyzed many of these frameworks or models, applied them in those projects, and discussed their results 
with the related departments. As the conclusion, although these researches can provide many useful experiences, few of them can be applied perfectly in innovation enterprises in China. The PRM model provides only indicators but evaluate method, and the indicators are too abstractive for unexperienced administrators in developing countries to individualize and use. The evaluation method in EAF of India can not reflect the non-linear diversity between performance levels because of the inherent shortcoming of weighted mean method. And the yardstick of EAF is too fixed to apply in different decisions. The other evaluation frameworks all focused one special type of IT projects and can hardly be used in other types. So we designed the new framework based on the investigation results and the related existing researches.

\section{THE PERFORMANCE EVAlUATION MODEL}

\section{A. The Indicator System.}

To reflect the whole performance of an CAI system, the performance evaluation model contains 14 groups of indicators (43 detailed indicators totally) of 5 domains:

Innovation Quality Domain. Innovation quality is a direct performance factor as the final output of CAI systems. To contain all key aspects on service chain in various systems, this domain includes "Innovation Effect and Service Delivery Speed", "User Convenient", and "Service Focus".

Technology Domain. Technology is the inner driven power of CAI system. The characters of technology can disclosure many potential performance trends which can not be shown by service domain alone. Here we divided the technology indicators into "Architecture", "Standard Compliance", "Security", "Reliability", "Extendibility".

System Life Domain. Sustainability focused on the longterm strategic performance. This domain consists of two environment factors that will influence the projects: "Organizational Environment" and "Law Environment".

Invest Benefit Domain. Comparing the cost with the benefit can directly reflect the efficiency of investment. Since the main purpose of most CAI systems is to gain longterm competitive benefit rather than economic benefit, we transform most of the cost and benefit indicators into nonmonetary form, such as "Reduction of Innovation Process", "New Mode of Innovation".

Reuse-Capability Domain. The capability to reuse a system in different environments is very important to a largescale enterprise group or an industry. Since most regular innovation processes in different companies are similar, developed a powerful system and reused it into all needed departments will obviously decrease the redundancy constructing and save the total budget. So we designed three important indicators to examine the reuse-ability performance: "Technology Reuse", "Function Reuse" and "Business Mode Reuse".

There are many ways to calculate the scores of basic indicators and domains based on detail indicators. Based on the results of investigation, we found the weighted mean method is effective and easy to apply. Here we select the well-known AHP method and Delphi method to decide weights.

To get accurate and quantitative scores for each indicator, we provide a detailed guideline which lists concrete score standards for all detail indicators considering most possible cases. Farther more, by using evidential-reasoning algorithm, the operator can get an accurate score even when he (her) can not assure the reference case in guideline exactly [7].

\section{B. The Evaluation Algorithm}

1) Nondimensionalization of Indicators.

By analyzing the investigation data, we found many of the indicators' levels belong to non-linear distributing. Table 2 shows an example. In this sample, we can hardly reflect the difference among each project with a linear nondimensionalization method such as weighted mean method. If we set $41 \%$ as the lower limit, the better systems (4 in sample) whose compliance rate greater than $91 \%$ will have the same score. Otherwise if we set $91 \%$ as the lower limit, then we are not able to compare the systems whose rate less than $91 \%$. So in both cases, the evaluation score will be useless.

TABLE II. THE SAMPLE DATA OF INDICATOR "COMPLIANCE WITH PROMISED RESPONSE TIME"

\begin{tabular}{|c|c|c|c|c|c|c|c|}
\hline $\begin{array}{c}\text { Compli } \\
\text { ance } \\
\text { rate }\end{array}$ & $\begin{array}{l}0 \%- \\
40 \%\end{array}$ & $\begin{array}{l}41 \%- \\
50 \%\end{array}$ & $\begin{array}{l}51 \%- \\
60 \%\end{array}$ & $\begin{array}{l}61 \%- \\
70 \%\end{array}$ & $\begin{array}{l}71 \%- \\
80 \%\end{array}$ & $\begin{array}{l}81 \%- \\
90 \%\end{array}$ & $\begin{array}{l}91 \%- \\
100 \%\end{array}$ \\
\hline $\begin{array}{c}\text { Sample } \\
\text { count }\end{array}$ & 0 & 1 & 1 & 0 & 1 & 2 & 9 \\
\hline
\end{tabular}

For the reason, we use a fuzzy nondimensionalization algorithm (formula 1) which can clearly reflect the nonlinear distribution of indicators. Fig. 1 explains that.

$$
R_{j}(x)= \begin{cases}0.5+0.5 \sin \left[\frac{\pi}{x_{j \max }-x_{j \min }}\left(x_{j}-\frac{x_{j \max }+x_{j \min }}{2}\right),\right. & x_{j \min }<x_{j}<x_{j m z x} \\ 0, & x_{j} \geq x_{j \max } \text { 或 } x_{j} \leq x_{j \min }\end{cases}
$$

$x_{j}$ is the original value of the indicator $x, R_{j}(x)$ is the dimensionless value, $x_{j \max }$ is the reasonable upper limit, $x_{j \text { min }}$ is the reasonable lower limit. This formula has been used in the performance evaluation of supply-chain system successfully [8], and so did in our investigation.

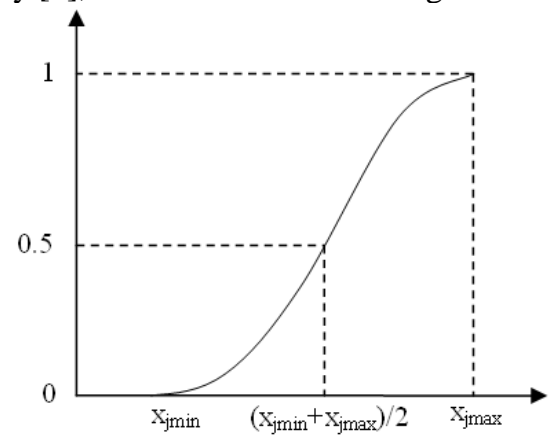

Figure 1. Fuzzy nondimensionalization algorithm 


\section{2) Evaluation Algorithm.}

The evaluation algorithm will integrate all the dimensionless indicator values into one integrated score for understanding the whole performance of one project or comparing the performances among different projects.

The first step is to integrate indicator values in each domain by weighted mean method. Since the non-linear problem has been solved by formula (1), the weighted mean method can work well in this step. After this step, we can get a vector of scores of five domains. Because of the obvious orthogonality of $p_{n}$, we need an algorithm which can integrate the five scores reasonably.

Suppose $P$ as the integrated score, $p_{n}(n=1, \ldots, 5)$ as the vector of scores of domains, $R$ as the failure risk of whole system, $r_{n}(n=1,2,3,4,5)$ as the failure risk of each domain, we can get hypothesis below:

Hypothesis 1: $P$ positively correlate with $p_{n}$, and negatively correlate with $R$.

Hypothesis 2: $p_{n}$ negatively correlate with $r_{n}$.

Hypothesis 3: The general risk control formula $R=1-\prod\left(1-r_{n}\right)$ is also suitable for $R$ and $r_{n}$.

Hypothesis1 and 2 can be accepted because of the general definition of performance and risk. Hypothesis 3 has been accepted in IT manage, control and audit for many years, which make it acceptable here too. Then we get formula (2).

$$
R=1-\prod\left(1-r_{n}\right), \quad R=f(P), \quad r_{n}=g\left(p_{n}\right), \quad n=(1 . .5)
$$

According to the normal risk control model $r=1-c$, set $f(P)=1-P+\varepsilon, \quad g\left(p_{n}\right)=1-p_{n}+\eta \quad, \quad$ then $P=\prod\left(p_{n}-\eta\right)+\varepsilon$. Formulate $P$ into $[0,1]$, and we can get the final evaluation formula (3):

$$
P=\left[\prod\left(p_{n}-\eta\right)+\eta^{5}\right] /\left[(1-\eta)^{5}+\eta^{5}\right] \quad, \quad n=(1, \ldots, 5)
$$

\section{3) Verification of the Evaluation Model}

We selected 5 various CAI projects as the sample to verify the evaluation model. Table 3 shows the basic attributes of the verify sample.

TABLE III. THE VERIFY SAMPLE

\begin{tabular}{|c|c|c|c|}
\hline \multirow{2}{*}{$\begin{array}{c}\text { Application } \\
\text { Type }\end{array}$} & $\begin{array}{c}\text { Knowledge } \\
\text { Management }\end{array}$ & $\begin{array}{c}\text { Collaborative } \\
\text { Design }\end{array}$ & E-Training \\
\cline { 2 - 4 } & 2 & 1 & 2 \\
\hline $\begin{array}{c}\text { Budget Scale } \\
\text { (RMB 1,000) }\end{array}$ & $\begin{array}{c}\text { Less than } \\
\mathbf{1 0 0}\end{array}$ & $\mathbf{1 0 0 - 1 , 0 0 0}$ & $\begin{array}{c}\text { More than } \\
\mathbf{1 , 0 0 0}\end{array}$ \\
\cline { 2 - 4 } & 2 & 2 & 1 \\
\hline
\end{tabular}

We first collected the original scores of detailed indicators by field examination and questionnaires, and then calculated the integrated scores using the model. Considering the lack of experience in first time use, we set the risk adjust factor $\eta$ equals 0.25 , and set the weights using AHP method. We also asked a group of professionals and experienced administrators in government to evaluate these projects independently. We compared the professional-group's evaluation results with that of our model.. The Pearson's correlation coefficient is 0.805 , and the significance level is less than 0.01 .

\section{The Budgeting Decision Model}

When examine a budget application about CAI project, we can use the budgeting decision model based on performance scores to assess the possibility to success, and decide whether to approve the investment. Fig. 2 shows the basic structure of the model.

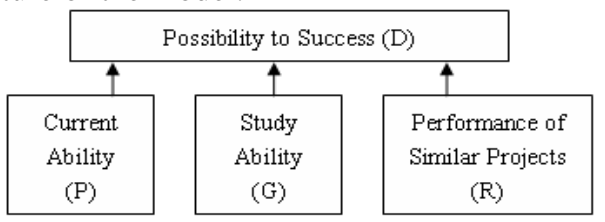

Figure 2. The Budgeting Decision Model

In this model, we supposed the possibility as a function depends on three main variables:

(1) $P$ - Current ability to run a CAI project of the applicant. This ability can be assessed using its historic performance scores of other projects. The formula is $P=\sum_{t=1}^{n}\left[t \sum_{j=1}^{m_{t}} S_{t j} \cdot d_{t j} /\left(n ! m_{t}\right)\right]$, in which $n$ is the count of recorded years, $m_{t}$ is the evaluated projects count in year $t$, $S_{t j}$ is the score of one project in year $t$, and $d_{t j}$ is the important weight to the project.

(2) $\quad S$ - Study ability on CAI constructing of the applicant. It reflects the future trend of the applicant, and $G=\sum_{i=1}^{n}\left(i-\frac{1+n}{2}\right) \cdot\left(A_{i}-\frac{1}{n} \sum_{j=1}^{n} A_{j}\right) /\left[\sum_{i=1}^{n} i^{2}-n \cdot \frac{(1+n)^{2}}{4}\right], A_{i}=\sum_{j=1}^{m} S_{i j} / m \quad, \quad$ in which $A_{i}$ is the average level of scores in year $i$, and other parameters are the same as fore formula.

(3) $\quad R$ - The performances of similar projects run by anybody. This item can give a reference to forecast the future performance of the application project, and can be easily gotten by using weighted mean method on all similar projects' performance scores in database.

Since there has no historic performance scores by now yet, we can only suppose the final decision function as the simplest theoretical form $D=a \sqrt{b(P+G) \cdot R}+c$, in which $a, b$ and $c$ are all adjust factors.

Some constructing design enterprises in Shanghai have accepted the conception of the model, and we will be upgrading the model by the accumulation of statistic data. 


\section{CONCLUSION}

Based on the investigation data and the compare research on different models, we proposed a performance based budgeting framework suitable for innovation-driven enterprises in China. The advantage of the performance evaluation model is its practical and objective, which has been proven by trial in some corporations. And the budget decision model has to be improved and verified in future because of the lack of historic data now. We will keep the research go on.

\section{REFERENCES}

[1] Joe Lin, Charley Ho, Wasim Sadiq and Maria E. Orlowska, "Using Workflow Technology to Manage Flexible e-Learning Services", Educational Technology \& Society 5(4) 2002.

[2] Gardner, L.; Sheridan, D.; White, D., "Computer Supported Learning - A Large-Scale, Web-Based Learning and Assessment System to Support
[3] Andres. Authority, Acceptance, Ability and Performance Based Budgeting Reforms. The International Journal of Public Sector Management, 2004(4/5): 332-344..

[4] OMB USA. Federal Enterprise Architecture [S]. 2005:1-17

[5] Peng Xizheng. A Discussion on CAI Performance Evaluation Framework. Chinese Informatization, 2005 6.27. (in Chinese)

[6] Mi Hong. Studies on Index System and Comprehensive Evaluation of Pre-assessment in CAI Item. Journal of Xiamen University, 2004(8):279-283 (in Chinese)

[7] Yang, J. B, Xu, D. L. Evidential Reasoning Algorithm for Multiple Attribute Decision Analysis under Uncertainty. Systems, Man and Cybernetics, Part A, IEEE Transactions on, 2002 (32/3):289-304.

[8] Ho Jiazhen, A research on Performance Evaluation of Integrated Supply Chain, Beijing Tsing Hua University Press, 2005:75-76 (in Chinese)

[9] Marjanovic, O. \& Orlowska, M. E. "Making Flexible Learning More Flexible", IEEE International Workshop on Advanced Learning Technologies IWALT'2000, 4-6 December 2000.

[10] Timothy K. Shih, Nigel H. Lin, Hsuam-Pu Chang, "An Intelligent ELearning System with Authoring and Assessment Mechanism", IEEE ATNA 2003. 